\title{
Fixed point results for Geraghty quasi-contraction type mappings in dislocated quasi-metric spaces
}

\author{
Joy C. Umudu ${ }^{1 *}$, Johnson O. Olaleru² and Adesanmi A. Mogbademu²
}

\section{"Correspondence:}

umuduj@unijos.edu.ng

'Department of Mathematics,

University of Jos, Plateau State,

Nigeria

Full list of author information is

available at the end of the article

\section{Springer}

\begin{abstract}
In this paper, fixed point results for a newly introduced Geraghty quasi-contraction type mappings are proved in more general metric spaces called $T$-orbitally complete dislocated quasi-metric spaces. Geraghty quasi-contraction type mappings generalize, among others, Ciric's quasi-contraction mappings and other Geraghty quasi-contractive type mappings in the literature. Fixed point results are obtained without imposing a continuity condition on the mapping, thereby further generalizing some other related work in the literature. An example is given to show the validity of results obtained.
\end{abstract}

MSC: Primary 47H10; secondary 54H25

Keywords: Fixed point; Dislocated quasi-metric space; Geraghty quasi-contraction type mapping

\section{Introduction and preliminaries}

Geraghty [1] generalized the Banach [2] contraction mapping in metric spaces by using an auxiliary function instead of a constant.

Let $F$ be the family of all functions $\beta:[0, \infty) \rightarrow[0,1)$ which satisfy the condition

$$
\lim _{n \rightarrow \infty} \beta\left(t_{n}\right)=1 \text { implies } \quad \lim _{n \rightarrow \infty} t_{n}=0 .
$$

Using such a function, Geraghty [1] proved the following theorem.

Theorem 1.1 ([1]) Let $(X, d)$ be a complete metric space and let $T$ be a self-mapping on $X$. Suppose that there exists $\beta \in F$ such that, for all $x, y \in X$,

$$
d(T x, T y) \leq \beta(d(x, y)) d(x, y),
$$

then $T$ has a unique fixed point $x^{*} \in X$ and $\left\{T^{n} x\right\}$ converges to $x^{*}$ for all $x \in X$.

Since then, some authors have generalized and extended the Banach contraction principle in diverse ways (see [3-7]).

c) The Author(s) 2020. This article is licensed under a Creative Commons Attribution 4.0 International License, which permits use, sharing, adaptation, distribution and reproduction in any medium or format, as long as you give appropriate credit to the original author(s) and the source, provide a link to the Creative Commons licence, and indicate if changes were made. The images or other third party material in this article are included in the article's Creative Commons licence, unless indicated otherwise in a credit line to the material. If material is not included in the article's Creative Commons licence and your intended use is not permitted by statutory regulation or exceeds the permitted use, you will need to obtain permission directly from the copyright holder. To view a copy of this licence, visit http://creativecommons.org/licenses/by/4.0/ 
Many extensions of Banach contraction mapping have also been investigated using different forms of contractive conditions. Asadi [8] proved some fixed point results satisfying certain contraction principles on a convex metric space. Özyurt [9] established fixed point results for extended large contraction via (c)-comparison function in a complete metric space while Özturk [10] introduced $F$-contraction and proved fixed point results for $F$ contractive iterates in a metric space. Some interesting results using other contractive conditions include [11-15].

In 2000, Hitzler [16] introduced a space known as dislocated metric space in which the self distance of points is not necessarily zero and showed that the popular Banach contraction mapping is also valid in the space. Dislocated metric space has applications in semantic analysis of logical programming, electronic engineering and in topology [16]. Zeyada et al. [17] further generalized the concept of dislocated metric space and introduced the idea of dislocated quasi-metric space. In this new notion, the symmetric property is also omitted. Some other papers have been published containing fixed point results for selfmappings with different contraction conditions in metric spaces and their generalizations including dislocated metric spaces and dislocated quasi-metric spaces (see [17-26]).

Definition 1.2 ([17]) Let $X$ be a non-empty set and let $d: X \times X \rightarrow \mathbb{R}^{+}$be a function such that the following are satisfied:

(i) $d(x, y)=d(y, x)=0$ implies that $x=y$;

(ii) $d(x, y) \leq d(x, z)+d(z, y)$ for all $x, y, z \in X$.

Then $d$ is called dislocated quasi-metric on $X$ and the pair $(X, d)$ is called a dislocated quasi-metric space.

As an improvement of $\alpha$-admissible maps introduced by Samet et al. [24] and Karapínar et al. [26], Popescu [5] introduced the following concepts, which were used to prove the existence and uniqueness of fixed point results in a complete metric space.

Definition 1.3 ([5]) Let $T: X \rightarrow X$ be a self-mapping and $\alpha: X \times X \rightarrow \mathbb{R}^{+}$be a function. Then $T$ is said to be $\alpha$-orbital admissible if $\alpha(x, T x) \geq 1$ implies $\alpha\left(T x, T^{2} x\right) \geq 1$.

Definition 1.4 ([5]) Let $T: X \rightarrow X$ be a self-mapping and $\alpha: X \times X \rightarrow \mathbb{R}^{+}$be a function. Then $T$ is said to be triangular $\alpha$-orbital admissible if $T$ is $\alpha$-orbital admissible and $\alpha(x, y) \geq 1, \alpha(y, T y) \geq 1$ imply $\alpha(x, T y) \geq 1$.

Lemma 1.5 ([5]) Let $T: X \rightarrow X$ be a triangular $\alpha$-orbital admissible mapping. Assume that there exists $x_{1} \in X$ such that $\alpha\left(x_{1}, T x_{1}\right) \geq 1$. Define a sequence $\left\{x_{n}\right\}$ by $x_{n+1}=T x_{n}$. Then, we have $\alpha\left(x_{n}, x_{m}\right) \geq 1$ for all $m, n \in \mathbb{N}$ with $n<m$.

The following definition by Ciric [25] on quasi-contraction mappings in metric spaces are also true for dislocated quasi-metric spaces.

Definition 1.6 ([25]) Let $T: X \rightarrow X$ be a self-mapping on a metric space. For each $x \in X$ and for any positive whole number $n$,

$$
O_{T}(x, n)=\left\{x, T x, \ldots, T^{n} x\right\} \quad \text { and } \quad O_{T}(x, \infty)=\left\{x, T x, \ldots, T^{n} x, \ldots\right\}
$$


The set $O_{T}(x, \infty)$ is called the orbit of $T$ at $x$ and the metric space $X$ is called $T$-orbitally complete if every Cauchy sequence in $O_{T}(x, \infty)$ is convergent in $X$.

It is clear that every complete dislocated quasi-metric space is $T$-orbitally complete. But the converse does not hold in general.

The purpose of this paper is to prove some fixed point results in dislocated quasi-metric space using new concepts of Geraghty quasi-contraction type self-mappings that the authors just introduced and proved fixed point results in the context of metric spaces [27]. The result is obtained by dropping the restriction of continuity and proving the existence and uniqueness of fixed point in an orbitally complete (which is a relaxation of completeness) dislocated quasi-metric space. This result generalizes many existing related work in the literature $[1-5,16,17,22-27]$.

\section{Main results}

Let $\Phi$ denote the class of the functions $\phi:[0, \infty) \rightarrow[0, \infty)$ which satisfy the following conditions:

(i) $\phi$ is non-decreasing;

(ii) $\phi$ is continuous;

(iii) $\phi(t)=0 \Longleftrightarrow t=0$.

First, we state the following new mapping introduced by the authors in [27].

Definition 2.1 Let $(X, d)$ be a metric space and $\alpha: X \times X \rightarrow \mathbb{R}^{+}$be a function. A selfmapping $T: X \rightarrow X$ is called an $\alpha-\phi$-Geraghty quasi-contraction type mapping if there exists $\beta \in F$ such that, for all $x, y \in X$,

$$
\alpha(x, y) \phi(d(T x, T y)) \leq \beta\left(\phi\left(M_{T}(x, y)\right)\right) \phi\left(M_{T}(x, y)\right),
$$

where $M_{T}(x, y)=\max \{d(x, y), d(x, T x), d(y, T y), d(x, T y), d(y, T x)\}$.

\section{Remark 2.2}

(i) From inequality (2) above, if $\alpha(x, y)=1, \phi(t)=t$ and $M_{T}(x, y)=d(x, y)$, then we have the Geraghty [1] contraction mapping defined on a metric space. In addition, if $\beta(t)=q$; where $q \in[0,1)$, we have the Banach contraction mapping [2]. Inequality (2) also generalizes, among others, those of Popescu [5], Karapínar [4, 28] and Cho et al. [3].

(ii) Definition 2.1 is also true for a dislocated quasi-metric space since every metric space is a dislocated quasi-metric space but the converse is not necessarily true. An example, which is inspired by Rahman and Sarwar [22], is provided to buttress this fact.

Example 2.3 Let $X=\mathbb{R}$ and $d(x, y)=|x|$ for all $x, y \in X$. Let $\beta(t)=\frac{1}{t}$ for all $t>0$. Then $\beta \in F$. Let $\phi(t)=2 t$ and a mapping $T: X \rightarrow X$ be defined by

$$
T(x)= \begin{cases}\frac{1}{2+x}, & \text { if } x \in[0,1] \\ 1, & \text { if } x>1 .\end{cases}
$$


Define a function $\alpha: X \times X \rightarrow[0, \infty)$ by

$$
\alpha(x, y)= \begin{cases}1, & \text { if } 0 \leq x, y \leq 1 \\ 0, & \text { otherwise }\end{cases}
$$

Then $T$ is an $\alpha-\phi$-Geraghty quasi-contraction type mapping defined on a dislocated quasimetric space but not on a metric space.

Theorem 2.4 Let $(X, d)$ be a T-orbitally complete dislocated quasi-metric space such that $T: X \rightarrow X$ is a self-mapping. Suppose $\alpha: X \times X \rightarrow \mathbb{R}^{+}$is a function satisfying the following conditions:

(i) $T$ is an $\alpha$ - $\phi$-Geraghty quasi-contraction type mapping.

(ii) $T$ is triangular $\alpha$-orbital admissible mapping.

(iii) There exists $x_{1} \in X$ such that $\alpha\left(x_{1}, T x_{1}\right) \geq 1$.

Then $T$ has a fixed point $x^{*} \in X$ and $\left\{T^{n} x_{1}\right\}$ converges to $x^{*}$.

Proof Let $x_{1} \in X$ such that $\alpha\left(x_{1}, T x_{1}\right) \geq 1$. Define a sequence $\left\{x_{i}\right\}$ by $x_{i+1}=T^{i} x$, for $1 \leq$ $i \leq n-1$. If $x_{i}=x_{i+1}$ for some $1 \leq i \leq n-1$, then obviously $T$ has a fixed point. Consequently, throughout the proof, we suppose that $x_{i} \neq x_{i+1}$ for all $i \geq 1$. By Lemma 1.5, used recursively, we have

$$
\alpha\left(x_{i}, x_{i+1}\right) \geq 1 \quad \forall i \geq 1
$$

By (2), for $1 \leq j \leq n$ we get

$$
\begin{aligned}
\phi\left(d\left(T^{i} x, T^{j} x\right)\right) & =\phi\left(d\left(T T^{i-1} x, T T^{j-1} x\right)\right) \\
& \leq \alpha\left(T^{i-1} x, T^{j-1} x\right) \phi\left(d\left(T T^{i-1} x, T T^{j-1} x\right)\right) \\
& \leq \beta\left(\phi\left(M_{T}\left(T^{i-1} x, T^{j-1} x\right)\right)\right) \phi\left(M_{T}\left(T^{i-1} x, T^{j-1} x\right)\right),
\end{aligned}
$$

where

$$
\begin{aligned}
\phi\left(M_{T}\left(T^{i-1} x, T^{j-1} x\right)\right)= & \phi\left(\operatorname { m a x } \left\{d\left(T^{i-1} x, T^{j-1} x\right), d\left(T^{i-1} x, T^{i} x\right), d\left(T^{j-1} x, T^{j} x\right),\right.\right. \\
& \left.\left.d\left(T^{i-1} x, T^{j} x\right), d\left(T^{j-1} x, T^{i} x\right)\right\}\right) \\
\leq & \phi\left(\delta\left[O_{T}(x, n)\right]\right),
\end{aligned}
$$

where $\delta\left[O_{T}(x, n)\right]=\max \left\{d\left(T^{i} x, T^{j} x\right): 0 \leq i \leq j \leq n\right\}$.

Note that, since the functions belonging to $F$ are strictly smaller than one, inequality (2) implies $\phi\left(d\left(T^{i} x, T^{j} x\right)\right) \leq \phi\left(M_{T}\left(T^{i-1} x, T^{j-1} x\right)\right)$ for all $0 \leq i \leq j \leq n$.

The case $\phi\left(M_{T}\left(T^{i-1} x, T^{j-1} x\right)\right)=\phi\left(d\left(T^{i} x, T^{j} x\right)\right)$ is impossible. For

$$
\begin{aligned}
\phi\left(d\left(T^{i} x, T^{j} x\right)\right) & \leq \beta\left(\phi\left(M_{T}\left(T^{i-1} x, T^{j-1} x\right)\right)\right) \phi\left(M_{T}\left(T^{i-1} x, T^{j-1} x\right)\right) \\
& \leq \beta\left(\phi\left(d\left(T^{i} x, T^{j} x\right)\right)\right) \phi\left(d\left(T^{i} x, T^{j} x\right)\right) \\
& <\phi\left(d\left(T^{i} x, T^{j} x\right)\right),
\end{aligned}
$$


is a contradiction. Thus, we conclude that $\phi\left(d\left(T^{i} x, T^{j} x\right)\right)<\phi\left(M_{T}\left(T^{i-1} x, T^{j-1} x\right)\right)$ for all $0 \leq$ $i \leq j \leq n$. Thus, the sequence $\left\{d\left(T^{i} x, T^{j} x\right)\right\}$ is positive and decreasing. Consequently, there exists $r \geq 0$ such that

$$
\lim _{i, j \rightarrow \infty} d\left(T^{i} x, T^{j} x\right)=r
$$

We claim that $r=0$. Suppose, on the contrary, that $r>0$. Then, from (4) we have

$$
\begin{aligned}
& \frac{\phi\left(d\left(T^{i} x, T^{j} x\right)\right)}{\phi\left(M_{T}\left(T^{i-1} x, T^{j-1} x\right)\right)} \leq \beta\left(\phi\left(M_{T}\left(T^{i-1} x, T^{j-1} x\right)\right)\right)<1, \\
& \lim _{i, j \rightarrow \infty} \beta\left(\phi\left(M_{T}\left(T^{i-1} x, T^{j-1} x\right)\right)\right)=1 .
\end{aligned}
$$

Since $\beta \in F$, by definition, it implies that

$$
\lim _{i, j \rightarrow \infty} \phi\left(M_{T}\left(T^{i-1} x, T^{j-1} x\right)\right)=0
$$

and so

$$
r=\lim _{i, j \rightarrow \infty}\left(d\left(T^{i} x, T^{j} x\right)\right)=0
$$

which is a contradiction.

Next, we show that the sequence $\left\{d\left(T^{i} x, T^{j} x\right)\right\}$ is Cauchy. On the contrary, suppose

$$
\epsilon=\lim _{m, n \rightarrow \infty} d\left(T^{n-1} x, T^{m-1} x\right)>0, \quad n \geq m .
$$

Using the triangle inequality,

$$
d\left(T^{n-1} x, T^{m-1} x\right) \leq d\left(T^{n-1} x, T^{n} x\right)+d\left(T^{n} x, T^{m} x\right)+d\left(T^{m} x, T^{m-1} x\right)
$$

implying

$$
d\left(T^{n-1} x, T^{m-1} x\right)-d\left(T^{n-1} x, T^{n} x\right)-d\left(T^{m} x, T^{m-1} x\right) \leq d\left(T^{n} x, T^{m} x\right) .
$$

Now, using $\phi$, we have

$$
\begin{aligned}
\phi\left(d\left(T^{n-1} x, T^{m-1} x\right)-d\left(T^{n-1} x, T^{n} x\right)-d\left(T^{m} x, T^{m-1} x\right)\right) \leq & \phi\left(d\left(T^{n} x, T^{m} x\right)\right) \\
\leq & \alpha\left(x_{n}, x_{m}\right) \phi\left(d\left(T^{n-1} x, T^{m-1} x\right)\right. \\
\leq & \beta\left(\phi\left(M_{T}\left(T^{n-1} x, T^{m-1} x\right)\right)\right) \\
& \times \phi\left(M_{T}\left(T^{n-1} x, T^{m-1} x\right)\right) .
\end{aligned}
$$

Taking the limits and using (6) we get

$$
\phi(\epsilon) \leq \lim _{m, n \rightarrow \infty} \beta\left(\phi\left(M_{T}\left(T^{n-1} x, T^{m-1} x\right)\right)\right) \phi(\epsilon),
$$




$$
1 \leq \lim _{m, n \rightarrow \infty} \beta\left(\phi\left(M_{T}\left(T^{n-1} x, T^{m-1} x\right)\right)\right) .
$$

Therefore $\lim _{m, n \rightarrow \infty} \beta\left(\phi\left(M_{T}\left(T^{n-1} x, T^{m-1} x\right)\right)\right)=1$ and so $\lim _{m, n \rightarrow \infty} \phi\left(M_{T}\left(T^{n-1} x, T^{m-1} x\right)\right)=$ 0 . Thus $\lim _{m, n \rightarrow \infty} d\left(T^{n-1} x, T^{m-1} x\right)=0$, which contradicts our assumption.

Thus, the sequence $\left\{d\left(T^{i} x, T^{j} x\right)\right\}$ is Cauchy. Since $X$ is $T$-orbitally complete, there exists $x^{*} \in X$ such that $\lim _{n \rightarrow \infty} T^{n} x=x^{*}$. To show that $T x^{*}=x^{*}$, suppose that

$$
d\left(x^{*}, T x^{*}\right)=\lim _{i \rightarrow \infty} d\left(T^{i} x, T x^{*}\right)>0 .
$$

Now,

$$
d\left(x^{*}, T x^{*}\right) \leq d\left(x^{*}, T^{i} x\right)+d\left(T^{i} x, T x^{*}\right)
$$

implying

$$
d\left(x^{*}, T x^{*}\right)-d\left(x^{*}, T^{i} x\right) \leq d\left(T^{i} x, T x^{*}\right) .
$$

Applying $\phi$, we have

$$
\begin{aligned}
\phi\left(d\left(x^{*}, T x^{*}\right)-d\left(x^{*}, T^{i} x\right)\right) & \leq \phi\left(d\left(T^{i} x, T x^{*}\right)\right) \\
& \leq \alpha\left(T^{i-1} x, x^{*}\right) \phi\left(d\left(T T^{i-1} x, T x^{*}\right)\right) \\
& \leq \beta\left(\phi\left(M_{T}\left(T^{i-1} x, x^{*}\right)\right)\right) \phi\left(M_{T}\left(T^{i-1} x, x^{*}\right)\right),
\end{aligned}
$$

where $M_{T}\left(T^{i-1} x, x^{*}\right)=\max \left\{d\left(T^{i-1} x, x^{*}\right), d\left(x^{*}, T x^{*}\right), d\left(T^{i-1} x, T^{i} x\right), d\left(x^{*}, T^{i} x\right), d\left(T^{i-1} x, T x^{*}\right)\right\}$.

Taking limits as $i$ tends to infinity gives

$$
\lim _{i \rightarrow \infty} \phi\left(d\left(x^{*}, T x^{*}\right)\right) \leq \lim _{i \rightarrow \infty} \beta\left(\phi\left(M_{T}\left(T^{i-1} x, x^{*}\right)\right)\right) \lim _{i \rightarrow \infty} \phi\left(d\left(x^{*}, T x^{*}\right)\right) .
$$

Also

$$
1 \leq \lim _{i \rightarrow \infty} \beta\left(\phi\left(M_{T}\left(T^{i-1} x, x^{*}\right)\right)\right)
$$

So, by the definition of $\beta \in F$, we get

$$
\begin{aligned}
\lim _{i \rightarrow \infty} \beta\left(\phi\left(M_{T}\left(T^{i-1} x, x^{*}\right)\right)\right)=1 & \rightarrow \lim _{i \rightarrow \infty} \phi\left(M_{T}\left(T^{i-1} x, x^{*}\right)\right)=0 \\
& \rightarrow \phi\left(d\left(x^{*}, T x^{*}\right)\right)=0 \\
& \rightarrow d\left(x^{*}, T x^{*}\right)=0,
\end{aligned}
$$

a contradiction. Thus, we obtain $d\left(x^{*}, T x^{*}\right)=0$. Similarly, $d\left(T x^{*}, x^{*}\right)=0$. That is, $x^{*}=T x^{*}$ and the fixed point of $T$ is $x^{*}$.

To ensure the uniqueness of a fixed point, consider the following hypothesis:

$(J)$ : For all $x \neq y \in \operatorname{Fix}(T)$ there exists $w \in X$ such that $\alpha(x, w) \geq 1, \alpha(y, w) \geq 1$ and $\alpha(w, T w) \geq 1$.

Fix $(T)$ denotes the set of fixed points of $T$. 
Theorem 2.5 Adding condition $(J)$ to the conditions of Theorem 2.4, we find that $x^{*}$ is a unique fixed point of $T$.

Proof From the proof of Theorem 2.4, $x^{*}$ is a fixed point of $T$. Assume that $x_{1}^{*}$ and $x_{2}^{*}$ are distinct fixed points of $T$. By $(J)$, there exists $w \in X$ such that $\alpha\left(x_{1}^{*}, w\right) \geq 1, \alpha\left(x_{2}^{*}, w\right) \geq 1$ and $\alpha(w, T w) \geq 1$. By condition (ii) in Theorem $2.4, \alpha\left(x_{1}^{*}, T^{n} w\right) \geq 1$ and $\alpha\left(x_{2}^{*}, T^{n} w\right) \geq 1$ for all $n \geq 1$. So

$$
\begin{aligned}
\phi\left(d\left(x_{1}^{*}, T^{n+1} w\right)\right) & \leq \alpha\left(x_{1}^{*}, T^{n} w\right) \phi\left(d\left(T x_{1}^{*}, T^{n+1} w\right)\right) \\
& \leq \beta\left(\phi\left(M_{T}\left(x_{1}^{*}, T^{n} w\right)\right)\right) \phi\left(M_{T}\left(x_{1}^{*}, T^{n} w\right)\right)
\end{aligned}
$$

for all $n \geq 1$, where

$$
\begin{aligned}
M_{T}\left(x_{1}^{*}, T^{n} w\right)= & \max \left\{d\left(x_{1}^{*}, T^{n} w\right), d\left(T^{n} w, T^{n+1} w\right), d\left(x_{1}^{*}, T x_{1}^{*}\right), d\left(T x_{1}^{*}, T^{n} w\right),\right. \\
& \left.d\left(x_{1}^{*}, T^{n+1} w\right)\right\} \\
= & \max \left\{d\left(x_{1}^{*}, T^{n} w\right), d\left(T^{n} w, T^{n+1} w\right), d\left(x_{1}^{*}, T^{n+1} w\right), d\left(x_{1}^{*}, T^{n} w\right)\right\} .
\end{aligned}
$$

We deduce, by Theorem 2.4, that the sequence $\left\{T^{n} w\right\}$ converges to a fixed point $z$. As $n \rightarrow \infty$ in the above inequality, we obtain $\lim _{n \rightarrow \infty} M_{T}\left(x_{1}^{*}, T^{n} w\right)=d\left(x_{1}^{*}, z\right)$. If $x_{1}^{*} \neq z$, then

$$
\frac{\phi\left(d\left(x_{1}^{*}, T^{n+1} w\right)\right)}{\phi\left(M_{T}\left(x_{1}^{*}, T^{n} w\right)\right)} \leq \beta\left(\phi\left(\left(M_{T}\left(x_{1}^{*}, T^{n} w\right)\right)\right)<1\right.
$$

and as $n \rightarrow \infty, \lim _{n \rightarrow \infty} \beta\left(\phi\left(M_{T}\left(x_{1}^{*}, T^{n} w\right)\right)\right)=1$ implies that $\lim _{n \rightarrow \infty} \phi\left(M_{T}\left(x_{1}^{*}, T^{n} w\right)\right)=0$. Thus $d\left(x_{1}^{*}, z\right)=0$, a contradiction. Therefore, $x_{1}^{*}=z$. Similarly, $x_{2}^{*}=z$. Thus $x_{1}^{*}=x_{2}^{*}$, a contradiction and hence the fixed point of $T$ is unique.

In inequality (2) taking $\phi(t)=t$, an $\alpha$-Geraghty quasi-contraction type mapping is obtained and Theorem 2.4 reduces to the following.

Corollary 2.6 Let $(X, d)$ be a T-orbitally complete dislocated quasi-metric space such that $T: X \rightarrow X$ is a self-mapping. Suppose $\alpha: X \times X \rightarrow \mathbb{R}^{+}$is a function satisfying the following conditions:

(i) $T$ is an $\alpha$-Geraghty quasi-contraction type mapping.

(ii) $T$ is triangular $\alpha$-orbital admissible mapping.

(iii) There exists $x_{1} \in X$ such that $\alpha\left(x_{1}, T x_{1}\right) \geq 1$.

Then $T$ has a fixed point $x^{*} \in X$ and $\left\{T^{n} x_{1}\right\}$ converges to $x^{*}$.

\section{Remark 2.7}

(i) Suppose the $\alpha$ - $\phi$-Geraghty quasi-contraction type mapping is defined on a metric space, then Theorem 2.4 reduces to the result obtained by the authors in [27].

(ii) Moreover, suppose continuity condition is imposed on the mapping $T$, if defined on a complete metric space, which is a stronger restriction than orbital completeness, $\phi(t)=t$ and $M_{T}(x, y)=\left\{d(x, y), d(x, T x), d(y, T y), \frac{d(x, T y)+d(y, T x)}{2}\right\}$ the result in Popescu [5] is obtained. 
(iii) The results in Karapinar [4, 28] and Cho et al. [3] are also corollaries to our result. Therefore, Theorem 2.4 is an improvement and a generalization of other related work and hence an addition to the library of mappings in the literature.

The following examples validate Theorem 2.4.

Example 2.8 Let $X=[0, \infty)$ and $d(x, y)=x$ for all $x, y \in X$. Let $\beta(t)=\frac{1}{1+t}$ for all $t>0$. Then $\beta \in F$. Let $\phi(t)=2 t$ and a mapping $T: X \rightarrow X$ be defined by

$$
T(x)= \begin{cases}\frac{1}{3} x, & \text { if } x \in[0,1], \\ 2 x, & \text { if } x>1 .\end{cases}
$$

Define a function $\alpha: X \times X \rightarrow[0, \infty)$ by

$$
\alpha(x, y)= \begin{cases}1, & \text { if } 0 \leq x, y \leq 1 \\ 0, & \text { otherwise }\end{cases}
$$

One can easily see that $X$ is a dislocated quasi-metric space but not a metric space. Also, the self-mapping $T$ is not continuous at $x=1$.

Condition (iii) of Theorem 2.4 is satisfied with $x_{1}=1$.

For condition (ii), let $x, y$ be such that $\alpha(x, y) \geq 1$. Then, $x, y \in[0,1]$, and $T x, T y \in[0,1]$. Moreover, $\alpha(y, T y)=\alpha(x, T x)=1$ and $\alpha\left(T x, T^{2} x\right)=1$. Thus, $\mathrm{T}$ is triangular $\alpha$-orbital admissible. Therefore, (ii) is satisfied.

Finally, we prove that condition (i) is satisfied. If $0 \leq x, y \leq 1$, then $\alpha(x, y)=1$ and

$$
\begin{aligned}
& \beta\left(\phi\left(M_{T}(x, y)\right)\right) \phi\left(M_{T}(x, y)\right)-\alpha(x, y) \phi(d(T x, T y))= \beta\left(\phi\left(M_{T}(x, y)\right)\right) \phi\left(M_{T}(x, y)\right) \\
&-\phi(d(T x, T y)) \\
&= \frac{2 M_{T}(x, y)}{1+2 M_{T}(x, y)}-2 T x \\
& \geq 0 .
\end{aligned}
$$

Therefore, $\alpha(x, y) \phi(d(T x, T y)) \leq \beta\left(\phi\left(M_{T}(x, y)\right)\right) \phi\left(M_{T}(x, y)\right)$ for $0 \leq x, y \leq 1$.

If $x \in[0,1], y>1$, or $x, y>1$ then, obviously, $\alpha(x, y)=0$ and we have

$$
\alpha(x, y) \phi(d(T x, T y)) \leq \beta\left(\phi\left(M_{T}(x, y)\right)\right) \phi\left(M_{T}(x, y)\right) .
$$

Therefore, all assumptions of Theorem 2.4 and Theorem 2.5 are satisfied, and hence $T$ has a unique fixed point $x^{*}=0$.

Example 2.9 Consider the set $X=\left\{\{0\} \cup\left\{\frac{1}{n}: n \in \mathbb{N}\right\} \cup \mathbb{N}\right\}$ and a dislocated quasi-metric $d(x, y)=|x-y|+x, \forall x, y \in X$. Let $\phi(t)=\frac{t}{2}$ and $\beta(t)=\frac{1}{t} \forall t>0$, then $\beta \in F$. Define the mapping $T: X \rightarrow X$ by

$$
T(x)= \begin{cases}\frac{1}{x}, & \text { if } x \geq 1, \\ x, & \text { otherwise }\end{cases}
$$

Also define the function $\alpha: X \times X \rightarrow \mathbb{R}^{+}$by $\alpha(x, y)=1 \forall x, y \in X$. 
$X$ is also a dislocated quasi-metric space but neither a metric space nor a dislocated metric space and the self-mapping $T$ is not continuous.

Condition (iii) of Theorem 2.4 is also satisfied with $x_{1}=1$.

Obviously, condition (ii) is satisfied. Let $x, y$ be such that $\alpha(x, y) \geq 1$. Then $x, y \in X$ and $T x, T y \in X$. Moreover, $\alpha(y, T y)=\alpha(x, T x)=1$ and $\alpha\left(T x, T^{2} x\right)=1$. Thus, $T$ is triangular $\alpha-$ orbital admissible and (ii) is satisfied.

Finally, we prove that condition (i) is satisfied. For $\forall x, y \in X, \alpha(x, y)=1$ and

$$
\begin{aligned}
& \beta\left(\phi\left(M_{T}(x, y)\right)\right) \phi\left(M_{T}(x, y)\right)-\alpha(x, y) \phi(d(T x, T y))= \beta\left(\phi\left(M_{T}(x, y)\right)\right) \phi\left(M_{T}(x, y)\right) \\
&-\frac{d(T x, T y)}{2} \\
&= \beta\left(\frac{M_{T}(x, y)}{2}\right)\left(\frac{M_{T}(x, y)}{2}\right) \\
&-\frac{|T x-T y|+T x}{2} \\
&=\left(\frac{2}{M_{T}(x, y)}\right)\left(\frac{M_{T}(x, y)}{2}\right) \\
&-\frac{|T x-T y|+T x}{2} \\
&= \frac{2-(|T x-T y|+T x)}{2} \\
& \geq 0 .
\end{aligned}
$$

Therefore, $\alpha(x, y) \phi(d(T x, T y)) \leq \beta\left(\phi\left(M_{T}(x, y)\right)\right) \phi\left(M_{T}(x, y)\right), \forall x, y \in X$.

Therefore, all assumptions of Theorem 2.4, Theorem 2.5 are satisfied, and hence $T$ has a unique fixed point at $x^{*}=1$.

\section{Acknowledgements}

The authors are grateful to the anonymous referees for their constructive and valuable remarks, comments and suggestions.

Funding

Not applicable.

Availability of data and materials

Not applicable.

\section{Competing interests}

The authors declare that they have no competing interests.

Authors' contributions

All authors contributed equally to the preparation of the paper. The authors read and approved the final manuscript.

Author details

'Department of Mathematics, University of Jos, Plateau State, Nigeria. ${ }^{2}$ Department of Mathematics, University of Lagos, Akoka, Lagos State, Nigeria.

\section{Publisher's Note}

Springer Nature remains neutral with regard to jurisdictional claims in published maps and institutional affiliations.

Received: 19 June 2020 Accepted: 13 October 2020 Published online: 02 November 2020

References

1. Geraghty, M.A.: On contractive mappings. Proc. Am. Math. Soc. 40(2), 604-608 (1973) 
2. Banach, S.: Sur les operations dans les ensembles abstraits et leur application aux equation intgrales. Fundam. Math. 3, 133-181 (1922)

3. Cho, S.H., Bae, J.S., Karapínar, E.: Fixed point theorems for $\alpha$-Geraghty contraction type maps in metric spaces. Fixed Point Theory Appl. 2013, 329 (2013)

4. Karapínar, E:: $\alpha-\psi$-Geraghty contraction type mappings and some related fixed point results. Filomat 28(1), 37-48 (2014)

5. Popescu, O.: Some new fixed point theorems for $\alpha$-Geraghty contraction type maps in metric spaces. Fixed Point Theory Appl. 2014, 190 (2014)

6. Singh, D., Chauhan, V., Asadi, M.: Some remarks on tripled fixed point theorems for sequence of mappings satisfying Geraghty contraction with applications. Commun. Nonlinear Anal. 3, 68-86 (2017)

7. Amini-Harandi, A., Emami, H.: A fixed point theorem for contraction type maps in partially ordered metric spaces and applications to ordinary differential equations. Nonlinear Anal. 72, 2238-2242 (2010)

8. Asadi, M.: Some results of fixed point theorems in convex metric spaces. Nonlinear Funct. Anal. Appl. 19(2), 171-175 (2014)

9. Gülyaz-Özyurt, S.: A fixed point theorem for extended large contraction mappings. Results Nonlinear Anal. 1(1), 231-235 (2018)

10. Öztürk, A.: A fixed point theorem for mappings with an $f$-contractive iterate. Adv. Theory Nonlinear Anal. Appl. 3(4), 231-235 (2019)

11. Monfared, H., Asadi, M., Azhini, M.: $f(\psi, \phi)$-Contractions for $\alpha$-admissible mappings on metric spaces and related fixed point results. Commun. Nonlinear Anal. 2(1), 86-94 (2016)

12. Asadi, M.: Remarks on the paper "Extension of Caristi's fixed point theorem to vector valued metric spaces". Nonlinear Funct. Anal. Appl. 19(4), 633-637 (2014)

13. Fulga, A.: Fixed point theorems in rational form via Suzuki approaches. Results Nonlinear Anal. 1(1), 19-29 (2018)

14. Rus, I.A.: Some variants of contraction principle in the case of operators with Volterra property: step by step contraction principle. Adv. Theory Nonlinear Anal. Appl. 3(3), 111-120 (2019)

15. Umudu, J.C., Olaleru, J.O., Mogbademu, A.A.: Fixed points of involution mappings in convex uniform spaces. Commun. Nonlinear Anal. 7(1), 50-57 (2019)

16. Hitzler, P.: Generalized metrics and topology in logic programming semantics. Ph.D. thesis, National University of Ireland, University College Cork (2001)

17. Zeyada, F.M., Hassan, G.H., Ahmed, M.A.: A generalization of fixed point theorem due to Hitzler and Seda in dislocated quasi-metric space. Arab. J. Sci. Eng. 31(1), 111-114 (2005)

18. Olaleru, J.O.: Some generalizations of fixed point theorems in cone metric spaces. Fixed Point Theory Appl. 2009, $657914(2009)$

19. Olaleru, J.O.: Common fixed points of three self-mappings in cone metric spaces. Appl. Math. E-Notes 11, 41-49 (2011)

20. Olaleru, J.O., Olaoluwa, H.O.: Common fixed points of four mappings satisying weakly contractive-like conditions in cone metric spaces. Appl. Math. Sci. 7, 2897-2908 (2013)

21. Olaleru, J.O., Stella, K.S., Olaoluwa, H.O.: Some fixed points of Ciric type contraction mappings in ordered g-partial metric spaces. Appl. Math. 5, 1004-1012 (2014)

22. Rahman, M.U., Sarwar, M.: Some new fixed point theorems in dislocated quasi metric space. Palest. J. Math. 5 , 171-176 (2016)

23. Aage, C.T., Salunke, J.N.: The results of fixed points in dislocated and dislocated quasi-metric space. Appl. Math. Sci. 2(59), 2941-2948 (2008)

24. Samet, B., Vetro, C., Vetro, P.: Fixed point theorems for $\alpha$ - $\psi$-contractive type mappings. Nonlinear Anal. 75 , 2154-2165 (2012)

25. Ciric, L.B.: A generalization of Banach's contraction principle. Proc. Am. Math. Soc. 45(2), 267-273 (1974)

26. Karapínar, E., Kumam, P., Salimi, P.: On $\alpha$ - $\psi$-Meir-Keeler contractive mappings. Fixed Point Theory Appl. 2013, 94 (2013)

27. Olaleru, J.O., Umudu, J.C., Mogbademu, A.A.: Fixed point results for generalized Geraghty quasi-contraction type mappings in metric spaces (2019, in review)

28. Karapínar, E.: A discussion on $\alpha$ - $\psi$-Geraghty contraction type mappings. Filomat 28(4), 761-766 (2014)

\section{Submit your manuscript to a SpringerOpen ${ }^{\circ}$ journal and benefit from:}

- Convenient online submission

- Rigorous peer review

- Open access: articles freely available online

- High visibility within the field

- Retaining the copyright to your article

Submit your next manuscript at $\boldsymbol{~ s p r i n g e r o p e n . c o m ~}$ 